\section{CARBOHYDRATE CHEMISTRY}

Advances in Carbohydrate Chemistry

Edited by Claude S. Hudson, Melville L. Wolfrom, Sidney M. Cantor. Vol. 7. Pp. ix +370 . (New York: Academic Press, Inc.; London: Academic Books, Ltd., 1952.) 7.50 dollars.

GINCE the first volume of "Advances in Carbo$\$$ hydrate Chemistry" was published in 1945, this series has established itself as indispensable both to those who work in this field and to those workers in other fields who wish to be well informed about sugar chemistry. The present volume maintains the high standard set by earlier volumes of the series. It contains eight articles, five from Britain, two from the United States and one from Germany.

The first of the articles, "The Methyl Ethers of the Aldopentoses and of Rhamnose and Fucose", contributed by R. A. Laidlaw and (the late) E. G. V. Percival, continues the series on the methyl ethers of the sugars started in earlier volumes. Methylation remains the backbone of structural studies in carbohydrate chemistry; this authoritative article will be of particular interest to those engaged in structural studies of the naturally occurring pentosans and of plant gums and mucilages.

The second article, "1,6-Anhydrohexofuranoses, a New Class of Hexosans", by R. J. Dimler, concerns two compounds, D-glueosan $\langle 1,4\rangle \beta\langle 1,6\rangle$ and D-galactosan $<1,4>\alpha<1,6\rangle$, which are of considerable interest in that they contain a 1,2-glycol system which is not attacked by sodium mataperiodate. This observation is important in view of the widespread use of and increasing dependence on this reagent to detect 1,2-glycol systems; but I am inclined to the opinion that the article would have been more valuable had it been delayed until work designed to test some of the theories advanced to explain this resistance to oxidation had been completed.

The next two articles concern the ketoses. C. P. Barry and J. Honeyman review "Fructose and its Derivatives", and J. V. Karabinos reviews "Psicose, Sorbose and Tagatose". Both articles give excellent accounts of their subjects, although the addition of a discussion of the fructose phosphates, especially of fructose 1,6-diphosphate, would have been welcome in view of their biochemical importance. No mention is made of the tagatose 6-phosphate described towards the end of 1949 by Totton and Lardy ${ }^{1}$. Since Dr. Karabinos's review contrins only two references (probably added in proof) to papers appearing at a date later than 1949 , it is probable that this publication of Totton and Lardy appeared after the review was completed. If this is so, then the delay between the completion of the article and its publication is considerable and strengthens my opinion that all articles of this type should bear the date of receipt of the manuscript by the editors.

The fifth article, "Acetals and Ketals of the Tetritols, Pentitols and Hexitols", by S. A. Barker and E. J. Bourne, is a valuable account of the preparation and properties of these compounds and includes an interesting discussion of the most probable manner in which a given carbonyl compound would condense with a given polyhydric alcohol. The sixth article, "The Glycals", by B. Helferich, has been transiated by W. Pigman from the original German. The unsaturated sugar derivatives are not as widely known as they might be, and it is to be hoped that this article on glycals will be followed fairly soon by one on the glycoseens. "The Chemistry of the 2-Amaino Sugars (2-Amino-2-Deoxy-Sugars)" is discussed by A. B. Foster and M. Stacey. Members of this group of compounds are of considerable interest, both intrinsically and as structural components of the mucopolysaccharides.

All these seven articles in the volume give long and apparently exhaustive tables of selected physical constants of derivatives of the compounds under review.

The final article, "The Size and Shape of some Polysaccharide Molecules", by C. T. Greenwood, reviews the application of physical methods to the determination of the molecular weights of polysaccharides other than starch and cellulose and shows the importance of the use of all possible methods of study before hazarding any suggestion as to the structure of any polysaccharide. In this article I found that the editorial policy of the use of expressions of the type $(0.7) 10^{8}$ and $0.7(10)^{6}$ in place of the more familiar $0.7 \times 10^{8}$ was at first confusing and later irritating.

The articles as a whole are well written. The printing is clear and the paper and binding excellent. A few trivial misprints were noted, among which were four cases of the value for the diffusion constant $(D)$ in the last article being given in terms of $10^{7}$ insterd of $10^{-7}$. The volume contrins comprehensive author and subject indexes; the entries in the latter were compiled using the recently adopted rules of carbohydrate nomenclature ${ }^{2}$, but the articles to which they refer were written before these rules came into force. There is, however, no confusion.

To sum up, the volume is a valuable contribution to the literature and should be in the possession of all who are interested in carbohydrate chemistry.

$$
\text { L. J. Haynes }
$$

1 Totton, E. L., and Lardy, H. A., J. Biol. Chem., 181, 701 (1949). J. Chem. Soc., 5108 (1952).

\section{CHEMICAL TECHNOLOGY}

\section{Encyclopedia of Chemical Technology}

Edited by Raymond E. Kirk and Donald F. Othmer. Vol. 4. Cineole to Dextrose; pp. xvi +969 . (1949.) Vol. 5, Di- to Explosions; pp. xvi +992 . (1950.) Vol. 6, Explosives to Furfural ; pp. xvi 1008 . (1951.) Vol. 7, Furneces to Iolite; pp. xvi+982. (1951.) Vol. 8, Ion Exchange to Metal Plating; pp. xvi + 944. (1952.) Vol. 9, Metal Surface Treatment to Penicillin; pp. xvi +944. (1952.) Vol. 10, Pentacene to Polymethine Dyes; pp. xvi +976 . (1953.) (New York and London: Interscience Publishers, Inc.) 25 dollars or $£ 815 s$. each volume.

A HUNDRED years ago, the chief source of A information bearing on chemical technology was Dr. Ure's "Dictionary of Arts, Manufactures and Mines". At the turn of the century Watt's "Dictionary of Chemistry" was available, but for general reference there was not much else. Thorpe's "Dictionary of Applied Chemistry" and Ullmann's "Enzyklopädie der Technischen Chemie" came into use later. The first volume of Thorpe's "Dictionary" had, however, appeared in 1890 .

Turning over the pages of Kirk and Othmer's "Encyclopedia of Chemical Technology", of which Vols. 1-10 have now appeared, the tremendous progress of chemical technology during the past fifty 